\title{
A Iniciativa de Cidadania Europeia num Contexto de Democracia ${ }^{1}$
}

\begin{abstract}
Dora Resende Alves
Doutora em Direito. Professora-auxiliar do Departamento de Direito da Universidade Portucalense Infante D. Henrique. Membro integrado do Instituto Jurídico Portucalense (IJP) da Universidade Portucalense Infante D. Henrique, como investigadora permanente do Instituto Jurídico Portucalense, na linha de investigação Capital, Labour, Tax and Trade. Com experiência em unidades curriculares no domínio do Direito da União Europeia, Direito Constitucional e da História do Direito. Doutora pela Universidad de Vigo (Espanha), com tese sobre tema do Direito da Concorrência da União Europeia, e mestre em Direito, área de Integração Europeia, pela Faculdade de Direito da Universidade de Coimbra. Formadora da Ordem dos Advogados no Centro Regional do Porto. http://orcid.org/0000-0003-4720-1400.dra@upt.pt
\end{abstract}

\section{Maria Manuela Magalhães}

Professora-associada da Universidade Portucalense Infante D. Henrique. Doutora em Direito - Ciências jurídico-políticas. Membro integrado e investigadora principal do Instituto Jurídico Portucalense (IJP) da Universidade Portucalense Infante D. Henrique, investigadora associada do Centro de Investigação em Direito Europeu, Econômico, Financeiro e Fiscal - Cideeff - Faculdade de Direito de Lisboa e investigadora colaboradora do Centro de Estudios Politicos y Constitucionales Comparados - CEPCC - Universidade Autônoma do Chile. http://orcid.org/0000-0003-4261-7271.mmdmms@upt.pt

\section{RESUMO}

Os valores da liberdade, democracia e estado de direito, os seus valores fundadores, e, disso consciente, a União Europeia (UE) mantém a construção em permanência no sentido de uma maior transparência de procedimentos, criando mecanismos de melhor funcionamento interinstitucional. O direito à iniciativa de cidadania europeia foi introduzido pelo Tratado de Lisboa como um instrumento inovador da democracia participativa transnacional. Pretende-se associar ativamente os cidadãos ao processo de decisão europeu, proporcionando-lhes uma forma indireta de direito de iniciativa legislativa. A questão prende-se com a aplicação efetiva das regras da UE como uma vertente importante para os europeus, que afeta, inelutavelmente, a sua vida diária. O problema nem sempre é a ausência de legislação da UE, mas, sim, o fato de nem sempre essa legislação ser aplicada de forma eficaz. Foi desenhada uma abordagem com especial enfoque na questão da vertente democrática do processo legislativo europeu e a forma de os cidadãos garantirem que o direito da União é aplicado de forma efetiva.

Palavras-chave: Iniciativa legislativa europeia. Legislação. União Europeia.

\section{THE EUROPEAN CITIZENS' INITIATIVE IN A CONTEXT OF DEMOCRACY}

ABSTRACT

The values of freedom, democracy and the rule of law are the mottoes of all European construction. With this in mind, the European Union (EU) maintains the ongoing construction towards greater transparency of procedures, creating mechanisms for better interinstitutional functioning. The right to the European citizens' initiative was introduced by the Treaty of Lisbon as a new instrument of transnational participatory democracy. The intention is to actively involve citizens in the European decision-making process by providing them with an indirect form of legislative initiative. Yet no successful initiative has given rise to a new legislative proposal, although in some cases the European Commission has taken into account the position of public opinion on specific aspects. The issue is the effective implementation of EU rules as an important strand for Europeans which inevitably affects their daily lives. The problem is not always the absence of EU legislation, but rather the fact that this legislation is not always applied effectively. It will thus be possible to infer the contribution of EU law texts to the achievement of this aspect. Keywords: European citizens initiative. Legislation. European Union.

SUMÁRIO

1 Introdução. 2 A Construção Europeia Democrática. 30 multilinguismo. 4 A iniciativa de cidadania europeia. 4.1 A Iniciativa de Cidadania Europeia - Casos. 5 Conclusão. 6 Referências.

Recebido em: 16/9/2019

Aceito em: $17 / 9 / 2019$

\footnotetext{
O texto parte da Comunicação oral apresentada na International Conference Democracy and Participation in the 21st Century, na Universidade de Lisboa, 12 a 15 de Julho de 2017, ISEG.
} 


\section{INTRODUÇÃO}

O modelo democrático foi o escolhido para a construção da União Europeia numa via de integração, na qual o cidadão, tal como no seu país de origem, tem direitos e deveres a desempenhar.

A União Europeia é, no seu lema, "Unida na diversidade". Tal lema começou a ser usado por volta do ano 2000 e foi pela primeira vez objeto de referência oficial no Tratado que estabelece uma Constituição para a Europa, assinado em 2004. ${ }^{2}$ Este lema significa que na União Europeia os europeus estão unidos, trabalhando em conjunto pela paz e pela prosperidade, e que o fato de existirem diferentes culturas, tradições e línguas na Europa é algo de positivo para o Continente. É esta união da diversidade europeia que deve ser preservada, nos mais variados aspectos da vida privada e cotidiana.

Essa diversidade é algo que deve ser preservado independentemente dos cenários futuros, porque os valores da dignidade humana, da liberdade e da democracia são valores fundamentais que foram conquistados com esforço e que permitiram a construção de uma Europa que resulta num projecto único no mundo. ${ }^{3}$

Cada vez mais os cidadãos europeus devem estar cientes dos seus direitos no seu país, na Europa e no mundo, para deles poderem se beneficiar. Embora alguns direitos sejam bem-conhecidos e aplicados eficazmente, continuam a existir lacunas e mal-entendidos. A eficácia dos direitos de cidadania, nacional ou da UE, depende desta tomada de consciência entre os cidadãos, governos nacionais e órgãos de poder local e regional.

A questão prende-se com a aplicação efetiva das regras da UE como uma vertente importante para os europeus, que afeta, inelutavelmente, a sua vida diária. O problema nem sempre é a ausência de legislação da UE, mas, sim, o fato de nem sempre essa legislação ser aplicada de forma eficaz. A aplicação e a execução do direito da UE é um desafio que exige uma maior ênfase na execução a fim de servir o interesse geral.

Atendendo aos pressupostos e objetivos supradelineados, foi dado especial enfoque à questão da vertente democrática do processo legislativo europeu e à forma de os cidadãos garantirem que o direito da União é aplicado de maneira efetiva. Será, assim, possível inferir o contributo dos textos do direito da União Europeia para a concretização de tal aspecto. $\mathrm{O}$ estado da arte, de pendor teórico-acadêmico, será coadjuvado e consolidado por meio da interpretação normativa sistemática e metodologicamente selecionada dos textos legais nacionais e do direito da União Europeia.

\footnotetext{
${ }^{2}$ Texto da Constituição Europeia em JOUE C 310 de 16.12.2004.

${ }^{3}$ Livro Branco da Comissão Sobre o Futuro da Europa - Reflexões e cenários para a UE27 em 2025. Documento COM(2017) 2025 final de 1‥3.2017, p. 2, 17
} 


\section{A CONSTRUÇÃO EUROPEIA DEMOCRÁTICA}

Os valores da liberdade, democracia e estado de direito ${ }^{4}$ são motes de toda a construção europeia, ontem e hoje, presentes na Declaração Schuman de $1950^{5}$ ou em documentos do momento em que traçam os vetores de ação atuais, ${ }^{6}$ além de plasmados no Tratado da União Europeia (TUE), no seu artigo $2 \stackrel{0}{ }$, e salvaguardados por intermédio do mecanismo do artigo 70, que aborda a violação da democracia. ${ }^{7}$

Valores comuns fruto da história europeia. ${ }^{8}$ Muito embora estes valores sejam fundadores, a UE é, muitas vezes, acusada de um deficit democrático, seja no funcionamento das instituições, seja na questão do direito do acesso aos documentos, seja nas, também atuais, questões da paridade de gênero. Disso consciente, a UE mantém a construção em permanência no sentido de uma maior transparência de procedimentos, acesso à informação pelos cidadãos e criação de mecanismos de melhor funcionamento interinstitucional. ${ }^{9}$

De outra forma, ${ }^{10}$ a democracia, a par dos direitos humanos e do Estado de direito, constitui também um dos três pilares do Conselho da Europa, sendo subscrito no preâmbulo da Convenção para a Proteção dos Direitos do Homem e das Liberdades Fundamentais (CE$\mathrm{DH})^{11}$ e motivando um grupo de especialistas próprio - a Comissão de Veneza $-{ }^{12}$ cujas apreciações são consideradas na elaboração de diversos documentos da UE.

É mediante a construção democrática com raízes na Convenção de Filadélfia de 1787, que se alcança uma possível homogeneidade da UE que assenta na incontornável diversidade dos 6 países fundadores e, hoje, 28, ou 27, se levarmos em conta a saída do Reino Unido pelo mecanismo do artigo 50 do TUE.

\footnotetext{
4 Nomeadamente, "O Tribunal de Justiça da União Europeia garante o respeito do Estado de direito." Comissão Europeia 2001/C 287/01. Governança-Um Livro Branco. COM(2001) 428 final, JOUE C 287 de 12.10.2001, p. 7.

5 Disponível em: http://europa.eu/european-union/about-eu/symbols/europe-day/schuman-declaration_pt.

${ }^{6}$ Comunicação da Comissão ao Parlamento Europeu, ao Conselho, ao Comitê Econômico e Social Europeu e ao Comitê das Regiões - Apoio à prevenção da radicalização que conduz ao extremismo violento. Documento COM(2016) 379 final de 14.6.2016.

7 Parecer do Comitê Econômico e Social Europeu 2017/C 034/02 sobre o "Mecanismo europeu de controlo do Estado de direito e dos direitos fundamentais", JOUE C 34 de 02.02.2017, p. 12, § 2.8.

8 Comunicação da Comissão ao Conselho e ao Parlamento Europeu sobre o artigo 7o do Tratado da União Europeia. Respeito e promoção dos valores em que a União assenta. Documento COM(2003) 606 final de 15.10.2003, p. 3, 13.

9 Relatório da Comissão ao Parlamento Europeu, ao Conselho, ao Comitê Econômico e Social Europeu e ao Comitê das Regiões - Reforçar os direitos dos cidadãos numa União da mudança democrática. Relatório de 2017 sobre a Cidadania da UE. Documento $\operatorname{COM(2017)~} 30$ final de 31.1.2017, p. 10.

${ }^{10}$ Comunicação da Comissão ao Parlamento Europeu e ao Conselho - Um novo quadro da UE para reforçar o Estado de direito. Documento COM(2014) 158 final de 11.03.2014, p. 2.

${ }^{11}$ Textos em http://www.coe.int/en/web/conventions/full-list.

${ }^{12}$ Ver em: http://www.venice.coe.int/webforms/events/. A Comissão Europeia para a Democracia através do Direito é conhecida pelo nome de Comissão de Veneza, cidade italiana onde se reúne, como órgão consultivo do Conselho da Europa sobre questões constitucionais. Foi criada em 1990 como um acordo entre 18 membros do Conselho da Europa, composta por especialistas independentes, nomeados por quatro anos pelos Estados-Membros, e reúne-se quatro vezes por ano.
} 
A defesa do Estado de direito (SILVA; ALVES, 2016, p. 238) está presente como princípio democrático e desafio, nomeadamente em matéria de alargamento, atento o artigo 49 do TUE a outros países europeus onde, atualmente, o conceito periga, embora não se deixem de registrar, paralelamente, progressos importantes. ${ }^{13}$

Certo de que se apresenta como um dos valores fundadores há quase 70 anos, a caracterização democrática da União Europeia de hoje está ainda aberta à discussão (MOURY, 2016 , p. 49) em vertentes como a transparência das tomadas de decisão, o controle das instituições ou a participação dos cidadãos na legitimidade de ambas as anteriores. Não é questionável, porém, que a União Europeia continua seguramente a constituir um dos locais do mundo em que a democracia e os direitos fundamentais são protegidos da melhora forma. ${ }^{14}$ São já 60 anos de paz num globo onde se vivem 60 conflitos militares, mas nenhuma dessas guerras em território da União. ${ }^{15}$

Em todas as situações, o valor universal da democracia deve ser promovido pela UE nas suas ações, parcerias e instrumentos. ${ }^{16}$ As instituições estão atentas aos esforços, ${ }^{17}$ tendo sido a sua própria geometria de poderes, com freios e contrapesos, tradução destas preocupações, bem como as diversas reformas sofridas pelas instituições da UE (PAIS, 2010). Será pela educação e formação nos valores comuns e nos princípios gerais do direito, estabelecidos nos artigos 1으 a 30 do TUE, que o caminho da UE deve ser trilhado para possibilitar aos aprendentes adquirir conhecimentos, aptidões e atitudes no sentido de uma cidadania ativa ${ }^{18}$ e democrática. Ao garantir uma educação de elevada qualidade para todos, em todos os graus de ensino a política de educação tem um papel de primeiro plano a desempenhar. Essas competências sociais, cívicas e interculturais permitirão reforçar, reafirmar e promover os valores democráticos da UE. ${ }^{19}$

Conforme a Comissão: "O funcionamento da União assenta na democracia representativa, o que implica transparência e uma cultura política assente na acessibilidade e na responsabilização, apoiada por um sistema eleitoral eficaz e por um eleitorado informado e partici-

\footnotetext{
${ }^{13}$ Comunicação da Comissão ao Parlamento Europeu, ao Conselho, ao Comitê Econômico e Social Europeu e ao Comitê das Regiões - Estratégia de alargamento da UE. Documento COM(2015) 611 final de 10.11.2015, p. 6, e Relatório Anual 2016/C 316/18 do Parlamento Europeu sobre os Direitos Humanos e a Democracia no Mundo em 2013 e a política da União Europeia nesta matéria, JOUE C 316 de 30.8.2016, p. 149.

14 Documento $\operatorname{COM}(2003) 606$, cit., p. 4.

${ }^{15}$ Conforme o discurso proferido pelo presidente da Comissão Europeia, Jean-Claude Juncker, no Instituto de Estudos Europeus da Universidade Católica de Louvain-la-Neuve (Bélgica) intitulado "A Europa hoje e de amanhã", referência SPEE$\mathrm{CH} / 17 / 341$ de 23 de fevereiro de 2017. Comemoraram-se em 25 de Março de 2017 os 60 anos dos Tratados de Roma que criaram a Comunidade Europeia da Energia Atômica (C. E. E. A. ou Euratom) (http://eur-lex.europa.eu/collection/eu-law/ treaties/treaties-force.html\#new-2-53) e a Comunidade Econômica Europeia (C. E. E.) (http://eur-lex.europa.eu/collection/ eu-law/treaties/treaties-founding.html).

16 Já pensa-se na Agenda 2030. Ver na Comunicação da Comissão ao Parlamento Europeu, ao Conselho, ao Comitê Econômico e Social Europeu e ao Comitê das Regiões - Proposta de um novo Consenso Europeu sobre o Desenvolvimento, O nosso mundo, a nossa dignidade, o nosso futuro. Documento $\operatorname{COM(2016)} 740$ final de 22.11.2013, p. 18.

17 Resolução 2015/C 313/03 do Comitê das Regiões sobre o tema "Melhorar o funcionamento da União Europeia: O Tratado de Lisboa e mais além", no JOUE C 313 de 22.9.2015, p. 9, § 4 e 6.

${ }_{18}$ Conclusões do Conselho e dos representantes dos governos dos Estados-Membros 2017/C 62/02, reunidos no seio do Conselho, sobre a inclusão na diversidade a fim de alcançar uma educação de elevada qualidade para todos, no JOUE C 62 de 25.2.2017, p. 3

19 Ibidem.
} 
pativo". ${ }^{20}$ Desta ideia retira-se a importância da educação, da defesa da diversidade linguística e do mecanismo da iniciativa de cidadania europeia, conforme pretende-se apresentar. ${ }^{21} \mathrm{Em}$ especial, esta realização desempenha um papel importante na aproximação dos cidadãos ao processo legislativo. ${ }^{22}$

\section{O MULTILINGUISMO}

Ligada à questão da diversidade, tônica sempre presente desde o lançamento da ideia da Europa comunitária, está o multilinguismo desde o primeiro momento. ${ }^{23} \mathrm{Hoje}$, o artigo 3, n. 3, § 40 do Tratado da União Europeia (TUE), estabelece como princípio estruturante o respeito pela riqueza da diversidade cultural e linguística da União e, do mesmo modo, o artigo 22 (SILVEIRA; CANOTILHO, 2013, p. 269) da Carta dos Direitos Fundamentais da União Europeia. A União Europeia tem 24 línguas oficiais e de trabalho, conforme correspondência ao artigo 55, n. 1 do TUE. É de sublinhar-se esta faculdade de a União Europeia permitir a utilização de 24 línguas oficiais, que surge como caracterizadora desta organização internacional, talvez, de uma forma ímpar. ${ }^{24}$ Nomeadamente, isso acontece na publicação do jornal oficial. ${ }^{25}$

Hoje, nos mais variados documentos e a propósito de assuntos muito diversos, regressa a afirmação do relevo do multilinguismo no sentido de o respeitar e o acolher. $O$ assunto pode surgir, logicamente até, a propósito da vocação de alargamento da UE ou tão somente da formação judiciária.

Neste item, no âmbito da formação judiciária, a formação multilinguística surge mencionada, ${ }^{26}$ cada vez com maior frequência, ${ }^{27}$ para reforçar as competências linguísticas das autoridades judiciais, advogados e outros interessados. ${ }^{28}$ Decorre também do fato de o Tribunal de Justiça da União Europeia ser uma instituição multilingue sem equivalente em nenhuma outra jurisdição do mundo, posto que cada uma das línguas oficiais da União pode ser língua de processo. $\mathrm{O}$ Tribunal de Justiça ${ }^{29}$ é, com efeito, obrigado a respeitar um multilinguismo

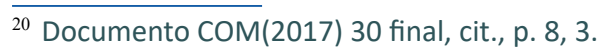

${ }^{21}$ Curiosamente duas ideias ligadas na última apresentação do instrumento que pretendemos focar neste pequeno estudo, no qual, por meio de uma iniciativa de cidadania europeia, que se repete pois fora recusada em 2013, se convida a Comissão "a melhorar a proteção das pessoas pertencentes a minorias nacionais e linguísticas e a reforçar a diversidade cultural e linguística da União" (comunicado de imprensa IP-17-776).

${ }^{22}$ Resolução 2017/C 408/02 do Parlamento Europeu, de 2 de abril de 2014, sobre a revisão intercalar do Programa de Estocolmo, no JOUE C 408 de 30.11.2017, p. 9, § 11.

${ }^{23}$ O primeiro regulamento da UE sobre o seu regime linguístico foi aprovado em 1958 e mantém-se em vigor, com alterações. O Regulamento № 1 do Conselho, de 15 de abril de 1958, estabelece o regime linguístico da Comunidade Econômica Europeia. Inicialmente tratava-se de dois regulamentos, este e o Regulamento no 1 do Conselho, de 15 de abril de 1958, que estabelece o regime linguístico da Comunidade Europeia da Energia Atômica.

${ }^{24}$ Basta consultar os endereços oficiais de grandes organizações internacionais para verificar a dificuldade de acesso em qualquer língua de Estados-Membros dessas mesmas organizações (ONU - www.un.org; UEO - www.weu.int; EFTA www.efta.int; OCDE - www.oedc.org).

${ }^{25}$ Relatório do Conselho 2015/C 97/3 sobre o acesso à legislação, JOUE C 97 de 24.3.2015, p. 3, § 14.

${ }^{26}$ Resolução do Parlamento Europeu 2013/C 251 E/7 de 14 de março de 2012 sobre formação judiciária, JOUE C 251 E de 31.8.2013, p. 44

${ }^{27}$ Resolução do Parlamento Europeu 2016/C 24/12, de 7 de fevereiro de 2013, sobre formação judiciária - coordenadores nos tribunais, JOUE C 24 de 22.1.2016, p. 99, § Q.

${ }^{28}$ Recomendação do Parlamento Europeu ao Conselho 2010/C 212 E/19 de 7 de Maio de 2009 referente ao desenvolvimento de um espaço de justiça penal na UE, JOUE C 212 E de 05.8.2010, p. 122, h), penúltimo §.

${ }^{29}$ Disponível em: http://curia.europa.eu/jcms/jcms/Jo2_7024/pt/.
} 
integral em razão da necessidade de comunicar-se com as partes na língua do processo e de assegurar a difusão da sua jurisprudência em todos os Estados-Membros. O mesmo Tribunal de Justiça afirma que a União Europeia é uma "comunidade de direito", ${ }^{30}$ que se concretiza também por meio dos seus aplicadores que são os juízes nacionais, que constituem um agente essencial do sistema jurisdicional da União Europeia, nomeadamente nos casos de aplicabilidade directa das suas normas.

Então, aqui as universidades têm um papel a desempenhar no ensino dos profissionais do direito, organismos profissionais, professores e estudantes de direito. ${ }^{31}$ Diga-se que o atual nível de formação em línguas estrangeiras, também em conjugação com o atual nível de conhecimento do direito comunitário, aliás, é insuficiente e limita o pleno exercício das possibilidades de cooperação judiciária. A necessidade de aumentar o conhecimento geral dos juízes nacionais em matéria de línguas estrangeiras é urgente, porque é do interesse público europeu desenvolver as competências linguísticas dos membros do poder judicial dos Estados-Membros. ${ }^{32}$

O sistema de educação, da primeira infância ao Ensino Superior, é convocado a levar em conta a aprendizagem de línguas refletindo a diversidade cultural. ${ }^{33}$ Está comprovado que o incentivo da educação na primeira infância constituiu uma medida que condiciona o percurso de aprendizagem ao longo da vida e o espírito democrático e de cidadania. ${ }^{34}$

O multilinguismo é aceito como elemento-chave do processo de integração europeia baseado em valores comuns e num patrimônio comum, ${ }^{35}$ numa perspectiva de direito fundamental e de patrimônio cultural, ${ }^{36}$ como um valor a incrementar. ${ }^{37}$

\section{A INICIATIVA DE CIDADANIA EUROPEIA}

A construção de uma Europa unida permitiu a paz que se vive na Europa há quase 70 anos, além de outros sucessos, como o alargamento, o mercado único, a moeda única ${ }^{38}$ ou a cidadania europeia. ${ }^{39}$ As escolhas assumidas hoje, porém, podem condicionar o percurso e o modo como a democracia funciona. ${ }^{40}$

\footnotetext{
30 No Acórdão do TJCE de 23 de 1986, Les Verts / Parlamento Europeu, Proc. C-294/83, Colect. 1986, p. 1.339, § 23.

31 Resolução do Parlamento Europeu 2013/C 251 E/07, cit., e Resolução do Parlamento Europeu 2016/C 24/12, cit.

${ }^{32}$ Resolução do Parlamento Europeu 2009/C 294 E/6, de 9 de julho de 2008, sobre o papel do juiz nacional no sistema jurisdicional europeu, no JOUE C 299 E de 3.12.2009, p. 29, § 6.

${ }_{33}$ Conclusões do Conselho 2017/C 62/2, cit., p. 5.

34 Ibidem.

35 Resolução do Conselho 2007/C 287/01 de 16 de Novembro de 2007 sobre uma Agenda Europeia para a Cultura, JOUE C 287 de 29.11.2007, p. 1-4.

${ }^{36}$ Conclusões do Conselho 2014/C 183/08, de 21 de maio de 2014, sobre o património cultural como recurso estratégico para uma Europa sustentável, JOUE C 183 de 14.6.2014, p. 36-38, e Comunicação da Comissão ao Parlamento Europeu, ao Conselho, ao Comitê Econômico e Social Europeu e ao Comitê das Regiões - Rumo a uma abordagem integrada do patrimônio cultural europeu. Documento COM(2014) 477 final de 22.7.2014.

${ }^{37}$ Relatório da Comissão ao Parlamento Europeu, ao Conselho, ao Comitê Econômico e Social Europeu e ao Comitê das Regiões sobre a execução, os resultados e a avaliação global do Programa "Europa para os Cidadãos" 2007-2013. Documento $\operatorname{COM}(2015) 652$ final de 16.12.2015, p. 2.

38 Discurso SPEECH/17/341, cit.

39 Relatório da Comissão $\operatorname{COM(2017)~} 30$ final/, cit., p. 3.

40 Livro Branco. Documento COM(2017) 2025, cit., p. 6.
} 
Os cidadãos da União Europeia são os reais atores de uma União de direito, ${ }^{41}$ se bem que, como reconhece o Parlamento Europeu, "os Estados-Membros são os principais responsáveis pela correta aplicação e execução do direito da União". ${ }^{42}$

Em articulação, a cidadania europeia faculta aos cidadãos europeus diversos direitos proclamados nos tratados e na Carta dos Direitos Fundamentais e mais do que uma forma de intervir na vida política democrática. As questões do exercício e conhecimento sobre a cidadania e participação ativa na vida democrática da União estão entre as prioridades definidas pela UE, que considera este domínio prioritário nas suas ações..$^{43}$ Os estudos demonstram que os europeus estão cada vez mais alertas na vivência do seu papel de cidadãos da União, e a percentagem de europeus que querem saber mais sobre os seus direitos continua a aumentar. ${ }^{44}$ Os europeus estão maioritariamente conscientes da sua cidadania da UE, mas nem sempre conhecem os direitos que dela decorrem. A cidadania da União Europeia comporta importantes direitos e liberdades e também a possibilidade de participação democrática e envolvimento ativo no processo decisório da UE, continuando a importar e definir a substância da cidadania europeia, porque muitas dúvidas se levantam ainda, mormente no campo dos direitos fundamentais. ${ }^{45}$

Uma das facetas da democracia é, então, permitir aos cidadãos envolverem-se nas tomadas de decisão por meio da participação no exercício da iniciativa legislativa. Não sendo a única forma de democracia participativa, ${ }^{46}$ é hoje promovido este instrumento. Acontece em âmbito nacional de variados países a reconhecerem, tal como Portugal, ${ }^{47}$ Brasil, ${ }^{48}$ EUA ou Suíça, e acontece na esfera da União Europeia. Não se trata do único direito político de imersão na democracia, ${ }^{49}$ mas é uma vertente muito promissora que se mostrou clara e de fácil concretização. Os resultados são escassos, tal como acontece no plano nacional, talvez atentando

${ }^{41}$ Comunicação da Comissão sobre a melhoria do controlo da aplicação do direito comunitário. Documento COM(2002) 725 final de 11.12.2002, p. 22.

42 Resolução 2017/C 316/28 do Parlamento Europeu de 10 de setembro de 2015, sobre o 30 e 31으 relatórios anuais sobre o controlo da aplicação do Direito da UE (2012-2013), JOUE C 316 de 22.9.2017, p. 249, § 20.

${ }^{43}$ Relatório da Comissão ao Conselho e ao Parlamento Europeu - Relatório de avaliação ex post relativo ao programa "Direitos Fundamentais e Cidadania" (2007 2013). Documento COM(2017) 69 final de 13.2.2017, p. 9, 11.

${ }^{44}$ Comunicado de imprensa da Comissão MEX/17/142 de 24 de janeiro de 2017.

45 Conforme analisado por SILVEIRA, Alessandra. Revista Julgar digital, n. 22, p. 181, 2014.

${ }^{46}$ Como, além do direito de petição, o caso da acção popular, prevista na Constituição da República Portuguesa, por previsão pelo artigo 52‥ Ver MAIOR, Mariana Sotto. "O direito de acção popular na Constituição da República Portuguesa", 1998, e GONÇALVES, Rubén Miranda. Novas alternativas ao exercício da democracia tradicional: a democracia participativa. Revista Jurídica UniCuritiba, p. 428, 2016.

${ }^{47}$ A iniciativa popular, na Constituição da República Portuguesa, por previsão pelo artigo 167o, no 1, depois da revisão constitucional de 1997, artigo 118 do Regimento da Assembleia da República no 1/2007 de 20 de agosto (com as últimas alterações de 2010) e regulada na Lei no 17/2003 de e de junho (com as alterações introduzidas pela Lei no 26/2012, de 24 de Julho; Lei Orgânica no 1/2016, de 26 de agosto; Lei no 52/2017, de 213 de julho e Declaração de Retificação no 24/2017, de 5 de setembro). Disponível em: http://www.parlamento.pt/EspacoCidadao/paginas/direitoiniciativalegislativa.aspx. Disponível em esquema em: http://www.helenaroseta.pt/documentos/1489938103K4pPC4mm5Uz690U1.pdf. Acesso em: 11 set. 2017.

${ }^{48}$ Neste país já por quatro vezes projetos de lei de iniciativa popular foram aprovados como lei em casos de violência que mobilizaram a opinião pública, como a primeira utilização que resultou na Lei no 8.930 de 7/9/1994.

${ }^{49}$ European Comission. EU Citizenship Report 2017 Strengthening Citizens' Rights in a Union of Democratic Change. 2017, p. 17. 
na juventude do instrumento, contudo, a utilização deste é uma via importante mesmo que apenas pela aprendizagem que resultam de contributos sem sucesso efetivo. Busca-se capacitar os cidadãos para influenciarem a agenda política. ${ }^{50}$

Por um lado, como referido, os europeus estão cada vez mais conscientes do seu estatuto de cidadãos da União, e a percentagem de europeus que querem saber mais sobre os seus direitos continua a aumentar. Por outro lado, cada vez mais a UE toma medidas para melhor dar a conhecer os direitos de cidadania, ${ }^{51}$ nomeadamente fomentando o envolvimento cívico dos jovens, para quem uma maior utilização da tecnologia pode traduzir uma maior adesão. ${ }^{52}$

O direito à iniciativa de cidadania europeia, plasmado no Regulamento (UE) n. 211/2011 de 2011, ,3 $^{3}$ foi introduzido pelo Tratado de Lisboa (artigos 11, n. 4 do TUE e 24, § 4, TFUE). Este tratado de revisão reforça a cidadania da União e melhora o seu funcionamento democráti$\mathrm{Co}^{54} \mathrm{com}$ este instrumento inovador da democracia participativa transnacional em vigor desde abril de 2012. Permite que um milhão de cidadãos da UE de, pelo menos, sete Estados-Membros, convidem a Comissão Europeia a apresentar propostas legislativas em domínios da competência da União Europeia, como condições de admissibilidade jurídica. Ainda, devem dizer respeito a matérias da competência da Comissão em apresentar uma proposta legislativa para efeitos de aplicação dos tratados. Deste modo, pretende-se associar ativamente os cidadãos ao processo de decisão europeu, proporcionando-lhes uma forma indireta de direito de iniciativa legislativa. Até hoje, mais de 6 milhões de cidadãos europeus assinaram uma iniciativa de cidadania europeia. Embora tenham sido apresentadas 58 iniciativas com sucesso, ${ }^{55}$ somente 36 foram registadas pela Comissão, ${ }^{56}$ das quais apenas 3 recolheram pelo menos 1 milhão de assinaturas. ${ }^{57}$ É depois de registada que se dá início a um processo de 12 meses para recolha das assinaturas em apoio da proposta de iniciativa de cidadania euro-

${ }^{50}$ Comunicado de imprensa da Comissão IP/17/649 de 22 de março de 2017.

${ }^{51}$ Documento $\operatorname{COM}(2017) 30$ final, cit., pp. 23 e 31, e EUROPEAN COMISSION. Did you know? 10 EU rights at a glance. Luxembourg: Publications Office of the European Union, 2014.

52 Resolução do Parlamento Europeu 2017/C 355/03, de 28 de outubro de 2015, sobre a Iniciativa de Cidadania Europeia, JOUE C 355 de 20.10.2011, p. 20.

${ }^{53}$ Regulamento (UE) no 211/2011 do Parlamento Europeu e do Conselho de 16 de fevereiro de 2011 sobre a iniciativa de cidadania, JOUE L 65 de 11.03.2011, pp. 1 a 22, e http://ec.europa.eu/citizens-initiative/public/welcome.

ver "A entrada em vigor do direito de iniciativa de cidadania europeia", 2012.

${ }^{54}$ Decisão (UE) 2017/599 da Comissão de 22 de março de 2017, no JOUE L 81 de 28.03.2017, p. 18, § 5.

55 Uma das mais recentes, publicitada pela Comissão que emitiu em 10.1.2017 um comunicado de imprensa (disponível em: http://europa.eu/rapid/press-release_IP-17-28_en.htm) que registava a Iniciativa de Cidadania Europeia (ICE) "Proibir o Glifosato - Proibição do glifosato e proteção das pessoas e do ambiente contra pesticidas tóxicos" que convida a Comissão "a propor aos Estados-Membros a proibição do glifosato, a rever o procedimento de aprovação de pesticidas a nível da UE e a estabelecer metas obrigatórias de redução da utilização de pesticidas". Este registo deu início ao necessário processo de 12 meses para recolha de assinaturas em apoio da proposta de Iniciativa de Cidadania Europeia pelos seus organizadores. Surgem, entretanto, mais três, ligadas à questão da saída do Reino Unido da União por exercício do artigo 50 do TUE, duas aceites ("Cidadania da UE para os europeus: unidos na diversidade apesar do jus soli e do jus sanguinis", pela Decisão (UE) 2017/599, cit., p. 18-19, e "Manutenção da cidadania europeia") e uma rejeitada ("Stop Brexit"), em 22.3.2017. Ainda é noticiada, em 29.3.2017, outra denominada Minority Safepack (comunicado de imprensa IP-17-776, cit. e Decisão (UE) 2017/652 da Comissão de 29 de março de 2017, JOUE L 92 de 6.4.2017, p. 100-104).

${ }^{56}$ Relatório da Comissão ao Parlamento Europeu, ao Conselho, ao Comitê Econômico e Social Europeu e ao Comitê das Regiões nos termos do artigo 25 do TFUE sobre os progressos rumo a uma efetiva cidadania da UE 2013-2016. Documento COM (2017) 32 final de 24.1.2017, p. 16.

${ }^{57}$ As propostas que foram bem-sucedidas são "A água e o saneamento são um direito humano! A água não é um bem comercial, mas um bem público!", "Stop Vivisection" (não à vivissecção) e "Um de nós". Disponíveis em: http://ec.europa.eu/ citizens-initiative/public/initiatives//successful. 
peia pelos seus organizadores, por 1 milhão de cidadão oriundos de, pelo menos, um quarto dos Estados-Membros da UE. Constitui um convite à Comissão a apresentar propostas legislativas, naturalmente em domínios da sua competência, não podendo, por tal, ser contrária aos valores da União. Ademais, é no prazo de um a três meses após o registo que cabe à Comissão apresentar a sua resposta, decidindo se intervém ou não, explicando as razões da sua posição com conclusões jurídicas e políticas. ${ }^{58}$ Até à presente data ainda não existiu nenhuma iniciativa totalmente bem-sucedida, isto é, não deu origem a nenhuma proposta legislativa, apesar de, em alguns casos, a Comissão Europeia ter considerado a posição da opinião pública sobre aspetos específicos. É, contudo, um instrumento de futuro de grande significado democrático a levar-se em conta.

A Comissão considera que a iniciativa de cidadania europeia está "plenamente operacional", ${ }^{59}$ mas reconhece que é possível melhorar a ferramenta. Nesse caminho, o Comitê das Regiões veio solicitar a revisão e a simplificação deste instrumento, a fim de o tornar mais convivial e acessível aos cidadãos, salientando que seria necessário à Comissão, por exemplo, não somente analisar, mas lançar um debate seguido de votação. ${ }^{60}$ Também o Parlamento Europeu foi mantendo-se atento a este mecanismo legal, procurando aperfeiçoá-lo no sentido de o tornar um instrumento de democracia participativa mais acessível e de fácil utilização, ${ }^{61}$ no sentido de prevenir obstáculos técnicos e burocráticos ${ }^{62}$ à sua utilização. ${ }^{63} \mathrm{~A}$ Comissão apresentou uma proposta de alteração do regulamento ${ }^{64} \mathrm{com}$ medidas para facilitar a organização da iniciativa de cidadania, facilitar o apoio a iniciativas e aumentar o impacto das iniciativas bem-sucedidas. Resultará mais uma vez da educação o reforço para o exercício da cidadania democrática nos valores da igualdade e da equidade, entendidos como distintos e complementares. ${ }^{65}$

O Comitê Econômico e Social Europeu criou o "Dia da Iniciativa de Cidadania Europeia", organizado em 2018 para 10 de abril, ${ }^{66}$ por ocasião da comemoração do 60 aniversário desde órgão.

\footnotetext{
${ }^{58}$ Comunicação da Comissão sobre a iniciativa europeia "A água e o saneamento são um direito humano! A água não é um bem comercial, mas um bem público!" Documento COM(2014) 177 final de 19.3.2014, p. 2, 1.

59 Documento COM (2017) 32 final, cit., p. 17

${ }^{60}$ Resolução 2015/C 313/3, cit., p. 9, § 4.

${ }^{61}$ Resolução do Parlamento Europeu 2010/C 212 E/14, de 7 de maio de 2009, que contém um pedido à Comissão no sentido da apresentação de uma proposta de regulamento do Parlamento Europeu e do Conselho relativo à aplicação da iniciativa de cidadania, no JOUE C 212 E de 5.8.2010, p. 99-105, e Resolução do Parlamento Europeu, de 28 de outubro de 2015, sobre a Iniciativa de Cidadania Europeia de 28 de outubro de 2015, P8_TA(2015)0382.

${ }^{62}$ Resolução do Parlamento Europeu 2017/C 378/25, de 13 de março de 2014, sobre a aplicação do Tratado de Lisboa no que respeita ao Parlamento Europeu, JOUE C 378 de 9.11.2017, p. 223, § 37.

${ }_{63}$ Disponível em: https://epthinktank.eu/2017/12/07/revising-the-european-citizens-initiative-eu-legislation-in-progress-policy-podcast/. Acesso em: 11 dez. 2017.

${ }^{64}$ Proposta de Regulamento do Parlamento Europeu e do Conselho sobre a iniciativa de cidadania europeia. Documento COM (2017) 482 final de 13.9.2017.

${ }^{65}$ Conclusões do Conselho 2017/C 62/02, cit., p. 4.

${ }^{66}$ Disponível em: https://www.eesc.europa.eu/pt/node/58609. Acesso em: 29 mar. 2018.
} 
Merece ainda a atenção do Provedor de Justiça, que observa e indaga no sentido de uma melhoria de eficácia. ${ }^{67}$

Desta forma, o processo legislativo europeu assume como característica essencial o fato de se tratar de um processo negocial que apela à participação das instituições europeias, dos Estados-Membros e, mesmo, dos cidadãos (MARRANA, 2012, p. 7).

Convém sublinhar que o instrumento da iniciativa de cidadania é diverso do direito de petição (mesmo artigo 24, § 2 e 3, TFUE) que assiste aos cidadãos europeus, e mais semelhante ao direito de iniciativa do Parlamento Europeu (artigo 225 TFUE) ou do Conselho (artigo 241 TFUE). ${ }^{68}$ Também não se insere normalmente na catalogação dos direitos políticos resultantes da cidadania europeia. Embora o reforço da participação dos cidadãos no processo democrático da UE seja prioridade atual da Comissão para os anos 2017-2019, ${ }^{69}$ este instrumento, objeto da nossa análise, é encarado como específico.

\subsection{A Iniciativa de Cidadania Europeia - Casos}

Conforme mencionado, e atentos aos desenvolvimentos mais recentes, desde a entrada em vigor do Regulamento (UE) n. 211/2011 sobre a iniciativa de cidadania, surgiram já mais de 36 iniciativas registradas pela Comissão. Desde a entrada em vigor deste instrumento, em 10 de abril de 2012, já 9 milhões de cidadãos europeus nele participaram ${ }^{70}$ com declarações de apoio recolhidas em toda a União Europeia. ${ }^{71}$

Afirmam-se, até o momento, como iniciativas bem-sucedidas, ${ }^{72}$ três propostas muito diferentes, visto terem alcançado uma subscrição suficiente e terem resultado em resposta da Comissão, ainda que por meio de comunicação. Nestas, a Comissão propõe-se tomar medidas adequadas (ou não num dos casos). ${ }^{73}$ Significa que, em tais casos, os organizadores da iniciativa de cidadania dispuseram do período de um ano para recolher as declarações de apoio necessárias que alcançaram e que foram confirmadas pelas autoridades competentes dos Estados-Membros. A Comissão, então, teve o prazo de três meses para analisar a iniciativa e tomar uma decisão sobre a mesma, o que fez por intermédio desses documentos COM.

\footnotetext{
67 Resolução do Parlamento Europeu 2018/C 35/21, de 25 de fevereiro de 2016, sobre o Relatório anual de 2014 do Provedor de Justiça Europeu, JOUE C 35 de 31.1.2018, p. 129. No caso, a Provedora Emily O’Reilly, em funções desde 1으 de outubro de 2013 (JOUE L 369 de 24.12.2014, p. 70).

${ }^{68}$ Ficha técnica sobre a União Europeia - 2017, consulta em 9.3.2017.

69 Relatório da Comissão COM (2017) 30 final, cit., p. 8.

${ }^{70}$ Resolução do Parlamento Europeu 2017/C 378/17, de 12 de março de 2014, sobre o Relatório de 2013 sobre a cidadania da União. Cidadãos da UE: os seus direitos, o seu futuro, JOUE C 378 de 9.11.2017, p. 147, § M.

${ }^{71}$ Relatório da Comissão ao Parlamento Europeu e ao Conselho sobre a aplicação do Regulamento (UE) no 211/2011. Documento COM(2018) 157 final de 28.3.2018.

${ }^{72}$ Disponível em: http://ec.europa.eu/citizens-initiative/public/initiatives//successful. Acesso em: 2 jun. 2017, e Resolução do Parlamento Europeu 2017/C 378/17, cit., p. 148, § 13.

${ }^{73}$ Vejam-se, respectivamente: Comunicação da Comissão sobre a iniciativa europeia "A água e o saneamento são um direito humano! A água não é um bem comercial, mas um bem público!". Documento COM (2014) 177 final de 19.3.2014; Comunicação da Comissão relativa à iniciativa de cidadania europeia "Um de nós". Documento COM (2014) 355 final de 28.5.2014; Comunicação da Comissão relativa à Iniciativa de Cidadania Europeia "Stop Vivisection". Documento COM (2015) 3773 final de 3.6.2015.
} 
O que não se alcançou ainda foi o resultado de conseguir uma proposta legislativa concreta que resulte em legislação aprovada. A Comissão não estará nunca obrigada a apresentar uma proposta legislativa na sequência de uma iniciativa, que, obviamente, terá de ser sempre em matéria no quadro da competência da União Europeia. Se a Comissão, no âmbito do poder discricionário que a caracteriza, decidir apresentar uma proposta legislativa, é desencadeado o processo legislativo normal: a proposta da Comissão é apresentada ao Parlamento Europeu e ao Conselho ou, dependendo da matéria, somente ao Conselho, e só terá força de ato legislativo se seguir toda a tramitação até à publicação no jornal oficial.

Pela primeira vez, em 19 de março de 2014 a Comissão Europeia decidiu dar resposta favorável à Iniciativa de Cidadania Europeia "A água e o saneamento são um direito humano! A água não é um bem comercial, mas um bem público!"; $;{ }^{74}$ uma iniciativa sobre o direito à água e ao saneamento a todos os cidadãos da UE; muito curiosa na medida em que vai ao encontro das recentes diretrizes da ONU para 2030,75 quando os 193 Estados signatários se propõem a garantir a disponibilidade e a gestão da água potável e do saneamento para todos como objetivo a atingir até ao ano de 2030.

Seguiu-se o tema "Stop Vivisection" (Fim à vivissecção), ${ }^{76}$ propondo um quadro legal europeu com vista a acabar com as experiências em animais.

Há, ainda, a iniciativa "Um de nós", 77 para criar uma protecção jurídica da dignidade, do direito à vida e da integridade de cada ser humano desde a concepção nas áreas de competência da UE.

Estão ainda a decorrer, entretanto, os prazos para preencher a adesão a nove iniciativas com os procedimentos em aberto. ${ }^{78}$

Relativamente às iniciativas recusadas, nas suas respostas a Comissão específica, com base nas condições estabelecidas no regulamento, mostra as razões da sua decisão de não registar a proposta em causa e informa os organizadores sobre todas as vias de recurso de que dispõe. seja porque não preencheram os requisitos exigidos pela legislação ao não reuniram apoio suficiente, como 18 delas, ${ }^{79}$ seja porque foram retiradas, como 14 delas, ${ }^{80} \mathrm{e}$, em ambos os casos, se tornaram obsoletas. A Comissão Juncker salienta ${ }^{81}$ que, desde que tomou posse, em novembro de 2014 , criou medidas concretas para melhorar o funcionamento deste instrumento, e, na sua vigência, apenas uma iniciativa foi recusada, um pedido no sentido de

\footnotetext{
$\overline{74}$ Disponível em: http://www.right2water.eu/. Acesso em: 2 jun. 2017.

75 Resolução intitulada "Transformar o nosso mundo: Agenda 2030 de Desenvolvimento Sustentável" adotada a 25 de setembro de 2015 e que entrou em vigor a 1ㅇ de janeiro de 2016. Disponível em: http://www.un.org/ga/search/view_doc. asp?symbol=A/RES/70/1\&Lang=E. Acesso em: 31 maio 2017.

${ }^{76}$ Disponível em: http://www.stopvivisection.eu/. Acesso em: 2 jun. 2017.

${ }^{77}$ Disponível em: https://oneofus.eu/. Acesso em: 2 jun. 2017.

${ }^{78}$ Disponível em: http://ec.europa.eu/citizens-initiative/public/initiatives/open. Acesso em: 5 jun. 2017.

${ }^{79}$ Disponível em: http://ec.europa.eu/citizens-initiative/public/initiatives/obsolete/conditions_not_fulfilled. Acesso em: 5 jun. 2017.

${ }^{80}$ Disponível em: http://ec.europa.eu/citizens-initiative/public/initiatives/obsolete. Acesso em: 5 jun. 2017.

${ }^{81}$ Comunicado de imprensa da Comissão de 15 de setembro de 2017 e documento da Comissão MEMO/17/3168 também de 15.9.2017.
} 
pôr termo à retirada do Reino Unido, claramente fora do âmbito do regulamento em causa. ${ }^{82}$ Também, a Comissão recuou na sua decisão inicial de não registrar a iniciativa "Não ao TTIP", 83 que fora anulada pelo Tribunal de Justiça da UE, conforme Relatório Anual (2017, p. 141).

A subscrição será realizada por qualquer cidadão da UE, ou seja, nacional de um Estado-Membro, com a idade mínima necessária para exercer o direito de voto nas eleições para o Parlamento Europeu. Para apoiar uma iniciativa, os cidadãos têm de preencher um formulário de declaração de apoio disponibilizado pelos organizadores em papel ou por via electrônica. A questão da recolha de número de assinaturas por país membro ${ }^{84}$ pode surgir como um entrave procedimental, independentemente do interesse do tema proposto.

Por exemplo, veja-se o caso da pretensão "Educação europeia de qualidade para todos", 85 que defendia que o futuro da Europa depende da educação, de como educar os cidadãos, sobre como eles aprendem e os objetivos pedagógicos comuns, refletindo os valores fundamentais da UE, que deveriam estar no centro da solução para os desafios atuais, lançada em 16.7.2012, não conseguindo prosseguir, ${ }^{86}$ quando, afinal, o núcleo do assunto prossegue pela UE nos mais recentes documentos da Comissão ${ }^{87}$ e corresponde, aliás, a um dos direitos fundamentais proclamado na Carta dos Direitos Fundamentais da União Europeia, artigo 14, o que nos leva de volta à questão da ideia de simplificar os moldes procedimentais e insistir na publicitação para o sucesso deste instrumento.

Uma outra pretensão, publicitada pela Comissão que emitiu em 10.1.2017 um comunicado de imprensa (http://europa.eu/rapid/press-release_IP-17-28_en.htm) que registrava a Iniciativa de Cidadania Europeia (ICE) "Proibir o Glifosato", convida a Comissão "a propor aos Estados-Membros a proibição do glifosato, a rever o procedimento de aprovação de pesticidas a nível da UE e a estabelecer metas obrigatórias de redução da utilização de pesticidas". Este registo deu início ao necessário processo de 12 meses para recolha de assinaturas em apoio da proposta de Iniciativa de Cidadania Europeia pelos seus organizadores. A Comissão volta a responder em 12.12.201788 por meio de comunicado de imprensa e compromete-se a apresentar, em 2018, uma proposta legislativa para reforçar a transparência e qualidade dos estudos utilizados na avaliação científica de substâncias.

\footnotetext{
82 "Stop Brexit". Disponível em: http://ec.europa.eu/citizens-initiative/public/initiatives/non-registered/details/3511. Acesso em: 15 set. 2017.

83 "Stop TTIP", to recommend to the Council to repeal the negotiating mandate for the Transatlantic Trade and Investment Partnership (TTIP) and not to conclude the Comprehensive Economic and Trade Agreement (CETA). Disponível em: http:// ec.europa.eu/citizens-initiative/public/initiatives/open/details/2017/000008. Acesso em: 15 set. 2017.

${ }^{84}$ Disponível em: http://ec.europa.eu/citizens-initiative/public/signatories?lg=en. Acesso em: 2 jun. 2017.

${ }^{85}$ Disponível em: www.EuroEdTrust.eu. Acesso em: 5 jun. 2017.

${ }^{86}$ Disponível em: http://ec.europa.eu/citizens-initiative/public/initiatives/obsolete/details/2012/000008. Acesso em: 5 jun. 2017.

${ }^{87}$ Vendo o próprio documento e todas as referências nele contidas a documentos anteriores no mesmo sentido de relevo à educação. Comunicação da Comissão ao Parlamento Europeu, ao Conselho, ao Comitê Econômico e Social Europeu e ao Comitê Das Regiões Desenvolvimento das escolas e um ensino da excelência para um melhor começo de vida. Documento COM (2017) 248 final de 30.5.2017.

${ }^{88}$ Disponível em: https://ec.europa.eu/food/plant/pesticides/glyphosate_en. Acesso em: 13 dez. 2017.
} 


\section{Humanos}

Democracia

Surgiram, entretanto, mais três, ligadas à questão da saída do Reino Unido da União por exercício do artigo 50 do TUE, duas aceites ("Cidadania da UE para os europeus: unidos na diversidade apesar do jus soli e do jus sanguinis"89 e "Manutenção da cidadania europeia") e uma rejeitada ("Stop Brexit"), ,90 em 22.3.2017. Ainda foi noticiada em 29.3.2017 outra denominada Minority Safepack. ${ }^{91}$

Já em 14.2.2018, a Comissão Europeia decidiu registar uma Iniciativa de Cidadania Europeia intitulada "Somos uma Europa acolhedora, deixem-nos ajudar!" ("We are a welcoming Europe, let us help!"), atentas às dificuldades dos Estados-Membros em lidar com a migração. ${ }^{92}$

Surge a iniciativa de cidadania intitulada "Amigos britânicos, fiquem conosco na UE!", no entendimento que o referendo de 2016 sobre o Brexit não foi um plebiscito cujo resultado seja vinculativo, mas, tão somente, um referendo público levado a efeito para que o Parlamento britânico pudesse ajuizar da opinião da população britânica naquele momento.

O instrumento da iniciativa europeia é, portanto, considerado pela UE como estando "plenamente operacional" o que, contudo, não o isenta de possíveis melhoramentos, conforme intenções expressas pelas instituições. ${ }^{93}$ Consideramos que este continua a ser importante manifestação de democracia, e a prática demonstra que os cidadãos europeus vêm descobrindo aos poucos este meio de contato com o exercício dos seus direitos de cidadania. A tônica continua, talvez, na necessidade de maior divulgação, maior visibilidade, maior proximidade com o cotidiano e, claro, maior adesão por parte dos meios de comunicação social para tornar transparente não apenas a sua plena existência, mas o seu real impacto.

Estando já exaustivo o elencar das iniciativas, diga-se que, ainda antes de terminar o ano de 2019, frequentes foram as novas iniciativas submetidas com admissibilidade, o que demonstra a maior visibilidade a utilização deste instrumento de democracia. ${ }^{94}$

\section{CONCLUSÃO}

A ideia de reforço de democracia não se esgota ou restringe ao funcionamento das instituições europeias, tampouco ainda à participação dos cidadãos nos procedimentos tendentes à adoção de medidas legislativas. $\mathrm{O}$ aprofundar da cidadania da União Europeia pode permitir

\footnotetext{
$\overline{89}$ Pela Decisão (UE) 2017/599, cit., p. 18-19.

${ }^{90}$ Disponível em: http://ec.europa.eu/citizens-initiative/public/initiatives/non-registered/details/3511. Acesso em: 5 jun. 2017.

${ }^{91}$ Conforme o comunicado de imprensa IP-17-776 e Decisão (UE) 2017/652 da Comissão de 29 de março de 2017, JOUE L 92 de 6.4.2017, p. 100-104.

92 Disponível em: http://europa.eu/rapid/press-release_IP-18-746_en.htm. Acesso em: 18 fev. 2018, e Decisão (UE) 2018/262 da Comissão de 14 de fevereiro de 2018 relativa à iniciativa de cidadania proposta intitulada "We are a welcoming Europe, let us help!", JOUE L 49 de 22.2.2018, p. 64-65.

${ }_{93}$ Resolução do Parlamento Europeu 2017/C 316/09, de 8 de setembro de 2015, sobre o seguimento da Iniciativa de Cidadania Europeia "Right2Water", JOUE C 316 de 22.9.2017, p. 102, § 1.

94 SILVA, Maria Manuela Magalhães; ALVES, Dora Resende e Ferreira, Maria João (2019). The value of new technologies in participatory democracy: The case of the European citizens' initiative. Doxa Comunicación, p. 37.
} 
aos cidadãos a oportunidade de interagirem e participarem na construção de uma Europa cada vez mais próxima, democrática e unida, enriquecida pela sua diversidade cultural ${ }^{95}$ nas mais variadas facetas.

O que entendemos por democracia continua ligado ao exercício das liberdades individuais e ao "desenho" da estrutura do Estado, quando se busca a relevância do cidadão. A aproximação de cada cidadão à construção europeia permanece ela própria em construção. Esta interação com os cidadãos está a ser e deve ser incrementada quer pela União Europeia quer pelos Estados-Membros, pelo bem da democracia, ${ }^{96}$ no "desenho" do Estado de direito. A iniciativa de cidadania europeia é mais um veículo nesse sentido, é já sentida como um instrumento político de recurso para o pulsar dos cidadãos europeus, mas não deu ainda os resultados necessários para se fazer sentida pelo cidadão comum, e vive com dificuldades técnicas ${ }^{97}$ de alguma forma identificadas e a que as instituições comunitárias já se mostraram sensíveis no sentido de introduzir melhorias com mudanças no regime jurídico aplicável. Tal como na realidade portuguesa, ainda não deu lugar a legislação aprovada, mas no plano europeu estão a ser exercitados os passos para alcançar nova legislação.

É, entretanto, muito pela educação e formação, criando uma cultura ativa de participação do cidadão para demonstrar e exercer o seu interesse cívico, que se manterá a diversidade da União Europeia como valor e unidade ${ }^{98}$ em todos os aspectos da vida e para além de todas as diferenças, pela promoção desde a primeira infância ao ensino universitário. ${ }^{99}$

\section{REFERÊNCIAS}

ALVES, Dora Resende. A entrada em vigor do direito de iniciativa de cidadania europeia. Revista Jurídica, Porto, Universidade Portucalense Infante D. Henrique, 15, 49-56, 2012. ISSN 0874-2839.

EUROPEAN COMISSION. EU Citizenship Report 2017 Strengthening Citizens' Rights in a Union of Democratic Change. Luxembourg: Publications Office of the European Union, 2017. ISBN 978-92-79-65323-0. DOI: 10.2838/51061.

EUROPEAN COMISSION. Did you know? 10 EU rights at a glance. Luxembourg: Publications Office of the European Union, 2014. ISBN 978-92-79-35765-7. DOI: 10.2775/22234.

GONÇALVES, Rubén Miranda. Novas alternativas ao exercício da democracia tradicional: a democracia participativa. Revista Jurídica UniCuritiba, Curitiba, v. 3, n. 44, p. 426-437, 2016. ISSN 2316-753X. DOI: 10.6084/m9.figshare.4610839.

MAIOR, Mariana Sotto. O direito de acção popular na Constituição da República Portuguesa. Documentação e Direito Comparado. 75/76. 1998. Disponível em: http://www.gddc.pt/actividade-editorial/pdfs-publicacoes/ 7576-g.pdf. Acesso em: 11 set. 2017.

MARRANA, Rui Miguel. O acesso à informação no quadro do funcionamento da União Europeia. In: Revista de Ciências Empresariais e Jurídicas, Instituto Superior de Contabilidade e Administração do Porto, 21, p. 7-42, 2012. ISSN 1646-1029.

MOURY, Catherine. A democracia na Europa. Lisboa: Fundação Francisco Manuel dos Santos, 2016. ISBN 978989-8838-49-0.

\footnotetext{
$\overline{95}$ Documento COM (2015) 652 final, cit., p. 2.

${ }^{96}$ Livro Branco. Documento COM (2017) 2025, cit., p. 6.

97 Documento COM (2018) 157 final, cit.

98 Conclusões do Conselho 2017/C 62/02, cit., p. 3.

99 Conclusões 2017/C 62/2 do Conselho e dos representantes dos governos dos Estados-Membros, reunidos no Conselho, sobre a inclusão na diversidade a fim de alcançar uma educação de elevada qualidade para todos, no JOUE C 62 de 25.2.2017, p. 3-7.
} 


\section{Humanos e \\ Democracia}

PAIS, Sofia Oliveira. O Tratado de Lisboa e a renovação das instituições da União Europeia. Cadernos $O$ Direito $O$ Tratado de Lisboa, Lisboa: Almedina, 5, p. 319-350, 2010.

SILVA, Maria Manuela Magalhães; ALVES, Dora Resende. Noções de Direito Constitucional e Ciência Política. 3. ed. Lisboa: Rei dos Livros, 2016. ISBN 978-989-88233-37-3.

SILVA, Maria Manuela Magalhães; ALVES, Dora Resende e Ferreira, Maria João. The value of new technologies in participatory democracy: The case of the European citizens' initiative. Doxa Comunicación, 28, 37-53, 2019. DOI: 10.31921/doxacom.n28a02 . Disponível em: http://hdl.handle.net/11328/2841.

SILVEIRA, Alessandra. Do âmbito de aplicação da Carta dos Direitos Fundamentais da União Europeia: recai ou não recai? - Eis a questão! Revista Julgar Digital, Coimbra: Coimbra Editora, n. 22, p. 179-209, 2014.

SILVEIRA, Alessandra; CANOTILHO, Mariana (coord.). Carta dos Direitos Fundamentais da União Europeia - comentada. Lisboa: Almedina, 2013. ISBN 978-972-40-5120-8.

TRIBUNAL DE JUSTIÇA. Relatório Anual 2016. Atividade Judiciária. Síntese da atividade judiciária do Tribunal de Justiça, do Tribunal Geral e do Tribunal da Função Pública da União Europeia. Luxemburgo: Serviço das Publicações da União Europeia. 2017. Disponível em: https://curia.europa.eu/jcms/upload/docs/application/pdf/201706/ra_2016_pt_web.pdf. Acesso em: 27 set. 2017. ISBN 978-92-829-2338-2. doi:10.2862/45870. 